Original

\title{
In vitro analysis of residual tooth structure of maxillary anterior teeth after different prosthetic finish line preparations for full-coverage single crowns
}

\author{
Bruna Borelli1,2), Roberto Sorrentino ${ }^{2)}$, Cecilia Goracci1), Fernando Zarone2), \\ and Marco Ferrari1) \\ 1)Department of Fixed Prosthodontics and Dental Materials, Tuscany School of Dental Medicine, \\ University of Florence and Siena, Siena, Italy \\ 2)Department of Prosthodontics, University of Naples "Federico II", Naples, Italy
}

(Received September 27, 2012; Accepted January 25, 2013)

\begin{abstract}
To evaluate residual dentin thickness (RDT) after different tooth preparations, 90 sound maxillary anterior teeth were selected and divided into 3 groups according to tooth type $(n=30)$, namely, maxillary central incisors, maxillary lateral incisors, and maxillary canines. In each group, specimens were randomly divided and prepared for single-crown coverage with shoulder ( $\mathrm{SHO}, n=10$, control), slight chamfer (CHA, $n=10)$, and knife-edge (KNE, $n=$ 10) finish lines. After tooth preparation, specimens were sectioned and divided into 4 subgroups (buccal, distal, palatal, and mesial) according to measurement area. RDT values were compared by using one-way ANOVA and Tukey's post hoc test $(P=0.05)$. Significant differences were found between $\mathrm{SHO}$ and the other two groups $(P<0.05)$ but not between CHA and KNE $(P>0.05)$. SHO was significantly more aggressive than CHA and KNE, which were comparable. Interproximal areas became critical due to thin RDT, which could potentially compromise the structural and biological integrity of teeth. The choice of finish line should be guided by careful clinical evaluation. (J Oral Sci 55, 79-84, 2013)
\end{abstract}

Correspondence to Dr. Bruna Borelli, Department of Fixed Prosthodontics and Dental Materials, Tuscany School of Dental Medicine, University of Florence and Siena, via A. Scarlatti 209 G, 80127 Naples, Italy

Fax:+39-81-7463018 E-mail: unabellabruna@gmail.com \& borelli.bruna@unisi.it
Keywords: residual dentin; finish line preparation; single crown; chamfer; knife-edge; shoulder.

\section{Introduction}

Metal-ceramic restorations offer reasonable esthetics (1) and successful long-term outcomes (2) and have thus been the gold standard in prosthetic dentistry for decades. However, increasing patient demand for improved esthetics has driven uptake of all-ceramic restorations (ACRs). The advantages of ACRs as compared with metal-ceramic restorations include improved biocompatibility and superior esthetics (3).

The strength of a prosthetic restoration depends not only on the fracture resistance of the material but also on a suitable preparation design with adequate material thickness. The assumption that increased material thickness automatically produces greater strength has been disproved (4). Current dental prosthetic treatments aim to preserve sound tissues and generally use techniques, including axial reduction and finish line preparation, that require removal of only limited sound tissue (5).

Metal-ceramic restorations require an average tooth reduction of $1.5-2 \mathrm{~mm}$ to incorporate the metal framework and opaque and glass ceramic (6-16). In contrast, ACRs do not need to mask the framework, and 1-1.5 $\mathrm{mm}$ is considered sufficient for incorporating the entire prosthetic crown. In certain cases, tooth-like appearance allows a reduction of $0.6-0.8 \mathrm{~mm}$ in preparation thickness at the level of the preparation margin (Table 1) (6-16).

Modern adhesive technologies and high-strength 


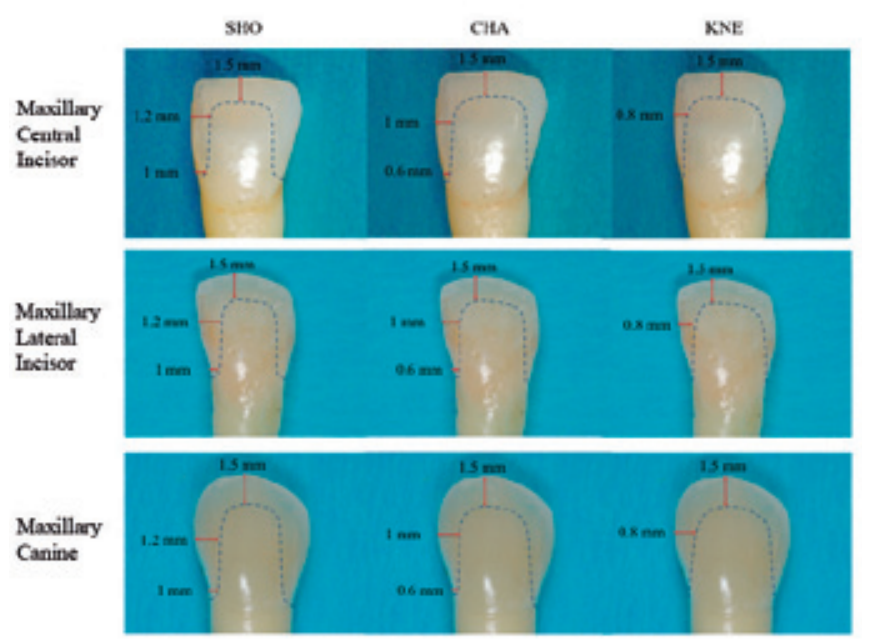

a)

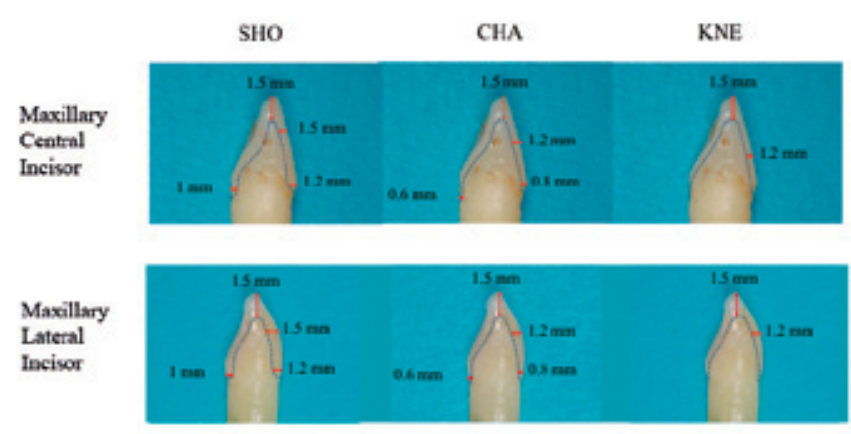

Maxillary
Canize

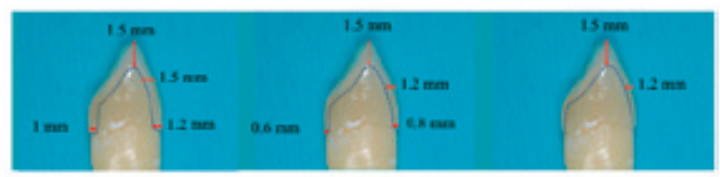

b)

Fig. 1 Preparation geometry and thicknesses in study samples $(\mathrm{SHO}=$ shoulder, $\mathrm{CHA}=$ chamfer, $\mathrm{KNE}=\mathrm{knife}-\mathrm{edge})$; a $)$ buccal view, b) interproximal view. The photographs were taken before teeth were embedded in resin blocks.

ceramic materials with enhanced fracture toughness may permit the use of minimally invasive preparation techniques, which prevent tooth weakening and pulp irritation (17). As a result, restoration dimensions with reduced coping thicknesses and less invasive finish lines, such as the slight chamfer, have been developed (18). Some reports indicate that, by preserving the greatest amount of sound tissue, the knife-edge finish line provides the most acute marginal finish line (4).

There are few reports on the amount of residual tooth structure remaining after prosthetic preparation (19). The aim of this in vitro study was thus to evaluate residual dentin thickness (RDT) after tooth preparation with shoulder (SHO), slight chamfer (CHA), and knife-edge (KNE) finish lines. The null hypothesis is that there is no association between the finish line preparation used and RDT for any surface area (buccal, mesial, palatal, distal) of maxillary central incisors, maxillary lateral incisors, or maxillary canines.

\section{Materials and Methods}

\section{Sample collection}

Ninety sound maxillary anterior teeth with no decay, previous restoration, or evidence of wear were selected. All teeth were extracted for periodontal reasons and were grouped according to type, irrespective of patient sex or race or whether they were from the right or left side. Central incisors, lateral incisors, and canines were included in the study.

To reduce the influence of pulp chamber size and shape variation, each tooth was examined by means of standardized digital radiographs $(70 \mathrm{kV}$ and $0.06 \mathrm{~s})$ on the mesial-distal and buccal-palatal planes. Only teeth
Table 1 Preparation thickness $(\mathrm{mm})$ in different areas of study samples

\begin{tabular}{lllll}
\hline Tooth Region & Area & SHO & CHA & KNE \\
\hline Incisal & - & 2 & 1.5 & 1.5 \\
& Buccal & 1.5 & 1.2 & 1.2 \\
\multirow{3}{*}{ Middle } & Interproximal & 1.2 & 1 & 0.8 \\
& Palatal & 1.5 & 1.2 & 1.2 \\
& Buccal & 1.2 & 0.8 & - \\
Cervical & Interproximal & 1 & 0.6 & - \\
& Palatal & 1 & 0.6 & - \\
\hline
\end{tabular}

$\mathrm{SHO}=$ shoulder, $\mathrm{CHA}=$ chamfer, $\mathrm{KNE}=$ knife-edge

with average coronal measures and pulp chamber widths, as specified in the anthropometric reports of Wheeler and Stambaugh, were included (20,21). Dental plaque, calculus, and periodontal fibers were removed with ultrasonic instruments and curettes. Teeth were disinfected with sodium hypochlorite $(5.25 \%)$ for $1 \mathrm{~min}$. Thereafter, the teeth were stored in $1 \%$ thymol solution at $37^{\circ} \mathrm{C}$ to avoid specimen dehydration. Each tooth was embedded in a block of self-curing acrylic resin (Dura Lay, Lang Dental Mfg. Co., Wheeling, IL, USA), leaving at least $2 \mathrm{~mm}$ of the root exposed so as to clearly reveal the cemento-enamel junction. A silicon impression (Affinis President PVS, Coltène/Whaledent AG, Altstätten, Switzerland) of each crown was made and then cut along the longitudinal axis on the mesial-distal and buccalpalatal planes. The impressions were used as templates to evaluate the amount of tooth reduction. The teeth were divided into 3 groups: maxillary central incisors (Group 1), maxillary lateral incisors (Group 2), and maxillary canines (Group 3). 


\section{Tooth preparation}

In each group of teeth, specimens were randomly divided for preparation with $\mathrm{SHO}(n=10$, control), $\mathrm{CHA}(n=10)$ or KNE $(n=10)$ finish lines. The preparation thicknesses (Table 1) and geometries (Fig. 1) were consistent with those in previous reports $(11,15,16,22,23)$. Regardless of preparation geometry, the finish line was placed at level of the cemento-enamel junction in all samples. Regarding tooth preparation, reduction of axial walls was performed with different burs, which were mounted on an air-turbine holder on a parallelometer surveyor (ISO Dentalfarm Surveyor-Parallelometer, A3502, Batch 10/06, C.I.E. Dentalfarm Srl, Torino, Italy). The total occlusal convergence (TOC) angle was set and controlled at $10^{\circ}$ to slightly taper the axial walls $(15,22,24,25)$. The following preparation protocols were adopted:

SHO finish line preparation: diamond cylindrical bur with rounded angles, Ø $2.1 \mathrm{~mm}$ (ISO 314141534021, $100-\mu \mathrm{m}$ granulometry, shape $\mathrm{n}^{\circ} 881$, Intensiv SA, Grancia, Switzerland); a half bur was used to measure and control the amount of tooth reduction.

CHA finish line preparation: diamond cylindrical bur with rounded angles, ø $1.2 \mathrm{~mm}$ (ISO 314141534012, 100- $\mu \mathrm{m}$ granulometry, shape $\mathrm{n}^{\circ} 881$, Intensiv SA, Grancia, Switzerland); a half bur was used to measure and control the amount of tooth reduction.

KNE finish line preparation: diamond knife edgeshaped bur, ø $1 \mathrm{~mm}$ (ISO 314250534010, 100- $\mu \mathrm{m}$ granulometry, shape $\mathrm{n}^{\circ} 863$, Intensiv SA, Grancia, Switzerland); the bur was used to remove undercuts of the axial walls.

For all samples, incisal reduction was performed manually to $1.5 \mathrm{~mm}$, and palatal reduction was performed manually to $1 \mathrm{~mm}$, with an occlusal preparation bur (ISO 314257524021, 100- $\mu \mathrm{m}$ granulometry, shape $\mathrm{n}^{\circ} 368$, Intensiv SA, Grancia, Switzerland). Connection areas between axial walls were adjusted manually, and all internal angles were rounded. During tooth preparation, the amount of tissue removed was controlled with silicon templates and a scaled probe.

\section{Sample measurement}

After tooth preparation, all teeth were sectioned perpendicularly to the longitudinal axis. A measurement location of $0.5 \mathrm{~mm}$ coronal to the cemento-enamel junction was used to verify the residual dentin thickness at the level of the finish line area because previous reports found this zone to be critical in achieving a reliable ferrule effect. Each section was divided into 4 subgroups according to the area to be measured (a: buccal, b: distal, c: palatal, and d: mesial) (Fig. 2). Then, as in the anthropometric study
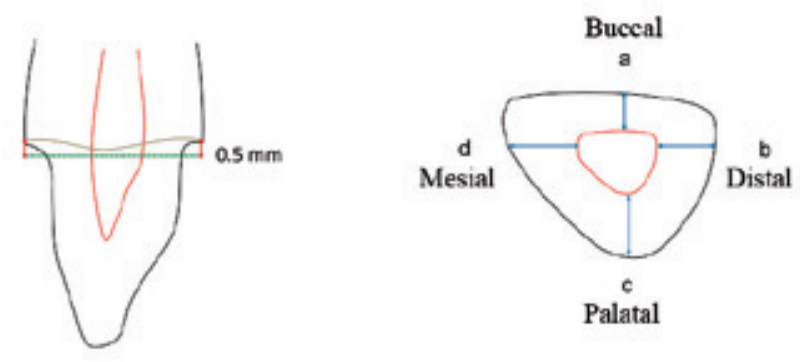

Fig. 2 Locations of sample measurement sites: location of cross-sectional cut (left side) and measured surfaces $(\mathrm{a}=$ buccal, $\mathrm{b}=$ distal, $\mathrm{c}=$ palatal, $\mathrm{d}=$ mesial) (right side).

of Stambaugh, these areas were measured using a digital caliper with 0.01-mm accuracy (Fig. 2) (20,21). Each measurement was performed 5 times at separate intervals ( 3 days apart) to avoid measurement error due to repetition. Maximum and minimum values were discarded, and the remaining 3 measurements were averaged.

\section{Statistical analysis}

The data were statistically analyzed using the software package SPSS 20.0 (SPSS Inc., Chicago, IL, USA). After verifying that data were normally distributed in each group (Kolmogorov-Smirnov test) and that group variances were homogeneous (Leven's test), one-way analysis of variance (ANOVA) was used to compare differences in RDT among finishing lines for each area of each tooth type. Tukey's test was used for multiple comparisons as needed. The level of statistical significance was set at $P<0.05$.

\section{Results}

Mean RDT values and the results of statistical analysis are summarized in Table 2. In subgroup 1a, differences were statistically significant $(P<0.05)$ for all preparations. In contrast, in subgroups $1 \mathrm{~b}, 1 \mathrm{c}$, and $1 \mathrm{~d}$, the differences were significant only for SHO $(P<0.05)$. In all subgroups (a-d) of Group 2, significant differences were found only for SHO $(P<0.05)$. In subgroups $3 \mathrm{a}$ and $3 \mathrm{~d}$, significant differences were found only for SHO $(P<0.05)$. However, significant differences in subgroup $3 \mathrm{~b}$ were noted for all preparations $(P<0.05)$, while in subgroup $3 \mathrm{c}$ significant differences were found only for CHA $(P<0.05)$.

\section{Discussion}

In the present study, all the null hypotheses were rejected $(P<0.05)$ because there were statistically significant differences between the analyzed finish lines for maxillary central incisors, lateral incisors, and canines. 
Table 2 Mean \pm SD residual dentin thickness $(\mathrm{mm})$ of analyzed samples

\begin{tabular}{|c|c|c|c|c|}
\hline \multicolumn{2}{|c|}{ Maxillary teeth } & \multirow{2}{*}{$\begin{array}{c}\text { Central incisor } \\
\text { Mean } \pm \text { SD }\end{array}$} & \multirow{2}{*}{$\begin{array}{c}\text { Lateral incisor } \\
\text { Mean } \pm \text { SD }\end{array}$} & \multirow{2}{*}{$\begin{array}{c}\text { Canine } \\
\text { Mean } \pm \text { SD }\end{array}$} \\
\hline & Finish lines & & & \\
\hline \multirow[t]{3}{*}{$\mathrm{a}$} & $\mathrm{SHO}$ & $1.55 \pm 0.32^{\mathrm{A}}$ & $1.59 \pm 0.34^{\mathrm{A}}$ & $1.88 \pm 0.51^{\mathrm{A}}$ \\
\hline & CHA & $2.39 \pm 0.19^{\mathrm{B}}$ & $2.35 \pm 0.06^{\mathrm{B}}$ & $2.43 \pm 0.37^{\mathrm{B}}$ \\
\hline & KNE & $2.50 \pm 0.11^{\mathrm{C}}$ & $2.37 \pm 0.11^{\mathrm{B}}$ & $2.44 \pm 0.30^{\mathrm{B}}$ \\
\hline \multirow[t]{3}{*}{$\mathrm{b}$} & SHO & $1.44 \pm 0.47^{\mathrm{A}}$ & $1.02 \pm 0.28^{\mathrm{A}}$ & $1.23 \pm 0.32^{\mathrm{A}}$ \\
\hline & CHA & $1.98 \pm 0.09^{\mathrm{B}}$ & $1.63 \pm 0.14^{\mathrm{B}}$ & $1.85 \pm 0.08^{\mathrm{B}}$ \\
\hline & KNE & $2.09 \pm 0.31^{\mathrm{B}}$ & $1.78 \pm 0.23^{\mathrm{B}}$ & $1.94 \pm 0.15^{\mathrm{C}}$ \\
\hline \multirow[t]{3}{*}{$\mathrm{c}$} & $\mathrm{SHO}$ & $1.71 \pm 0.42^{\mathrm{A}}$ & $1.99 \pm 0.67^{\mathrm{A}}$ & $2.43 \pm 0.34^{\mathrm{A}}$ \\
\hline & CHA & $2.69 \pm 0.38^{\mathrm{B}}$ & $2.57 \pm 0.32^{\mathrm{B}}$ & $2.94 \pm 0.52^{\mathrm{B}}$ \\
\hline & KNE & $2.86 \pm 0.28^{\mathrm{B}}$ & $2.56 \pm 0.22^{\mathrm{B}}$ & $2.89 \pm 0.41^{\mathrm{A}}$ \\
\hline \multirow[t]{3}{*}{ d } & SHO & $1.52 \pm 0.28^{\mathrm{A}}$ & $1.09 \pm 0.36^{\mathrm{A}}$ & $1.71 \pm 0.27^{\mathrm{A}}$ \\
\hline & CHA & $1.99 \pm 0.18^{\mathrm{B}}$ & $1.72 \pm 0.20^{\mathrm{B}}$ & $2.24 \pm 0.12^{\mathrm{B}}$ \\
\hline & KNE & $2.08 \pm 0.12^{\mathrm{B}}$ & $1.85 \pm 0.21^{\mathrm{B}}$ & $2.28 \pm 0.24^{\mathrm{B}}$ \\
\hline
\end{tabular}

$\mathrm{a}=$ buccal, $\mathrm{b}=$ distal, $\mathrm{c}=$ palatal, $\mathrm{d}=$ mesial, $\mathrm{SHO}=$ shoulder, $\mathrm{CHA}=$ chamfer, $\mathrm{KNE}=$ knife-edge

Statistically significant differences are indicated by the presence of different superscript letters. One-way ANOVA was used to independently analyze each subgroup $(P<0.05)$.

However, a statistically significant difference between CHA and KNE was noted only in subgroups $1 \mathrm{a}$ and $3 \mathrm{~b}$.

The strength of ACRs depends not only on the fracture resistance of the material but also on a suitable preparation design with adequate material thickness. SHO and CHA have been proposed by manufacturers for ACRs. However, some reports indicate that KNE is a promising alternative to CHA, as it is minimally invasive, particularly in anterior regions $(4,26)$. Nonetheless, the presence of a margin is regarded as paramount for contour precision and periodontal health (7,8,27-29), and excellent demarcation is required during the preparation and impression phases (27). Consequently, dental technicians sometimes have difficulty detecting KNE, as the finish line is no longer represented by a line but rather by an area. Furthermore, although KNE provides better sealing before cementation, seating is worse than that of horizontal preparations $(26,27)$.

Because of the recent emphasis on minimally invasive dentistry, the present study focused on more conservative finish lines. SHO is no longer indicated for ACRs, since there is no need to prepare the space for the metal framework and opaque ceramic layer, thus allowing clinicians to design more conservative preparation geometries. In addition, this invasive preparation may have biological consequences such as pulp irritation (30-33).

Several studies have investigated the biological complications of metal-ceramic fixed prostheses. The incidence of pulpal injury due to prosthetic preparation ranged from $2 \%-57.1 \%$ during observational periods of 2-25 years (34-43), and endodontic complications mainly affected anterior teeth $(41,43,44)$. In particular, one clinical study found that the incidence of pulpal necrosis in maxillary anterior teeth was $54.5 \%$ for multi-unit fixed dental prostheses and $19.2 \%$ for single crowns (44). However, the influence of confounding variables such as preoperative restorative and periodontal status, operator skill, sex, and tooth type must also be considered.

The results of this in vitro study did not show a statistically significant difference between CHA and KNE in relation to satisfactory tooth removal, which suggests that $\mathrm{KNE}$ is not a more conservative prosthetic treatment than CHA, even if both are less invasive than SHO.

There were differences between CHA and KNE on the buccal surface of central incisors and the distal surface of canines. These differences may be due to the greater convexity of those areas; however, only a slight difference $(P=0.042)$ was found for maxillary central incisors. No statistically significant difference $(P=0.063)$ were seen between SHO and KNE in Group 3c, perhaps because of the need to shape the cingulum.

Only teeth with average measures, ie, with values comparable to those reported in the work of Wheeler and Stambaugh, were included in the present study $(20,21)$. Nevertheless, anatomic and chromatic variation should be considered when planning a prosthetic treatment in an esthetically important area. In particular, the RDT in interproximal areas was the thinnest for all the finish lines; consequently, in patients with teeth smaller than those included in this study, careful attention should be paid in such areas because of potential interference with the structural and biologic integrity of teeth.

For all the investigated finish lines, the minimum thickness required for incorporating the framework and veneering ceramic was chosen on the basis of previous reports (6-8), although more-invasive preparations might 
be necessary in clinical practice. The mean RDT reported for SHO clearly showed that it was the most invasive finish line and that CHA and KNE were comparable.

Within the limitations of the present in vitro study, our results indicate that $\mathrm{SHO}$ was significantly more aggressive than either CHA or KNE and that CHA and KNE were comparable with respect to tissue removal. In all the investigated finish lines, the interproximal areas became critical due to thin RDT, which might interfere with the structural and biological integrity of teeth. Due to the anatomic and chromatic variability of teeth, as well as the operator-sensitive preparation technique, further investigations will be necessary to confirm our results.

\section{References}

1. Donovan TE (2009) Porcelain-fused-to-metal (PFM) alternatives. J Esthet Restor Dent 21, 4-6.

2. Näpänkangas R, Raustia A (2008) Twenty-year follow-up of metal-ceramic single crowns: a retrospective study. Int $\mathrm{J}$ Prosthodont 21, 307-311.

3. Kelsey WP, Cavel T, Blankenau RJ, Barkmeier WW, Wilwerding TM, Latta MA (1995) 4-year clinical study of castable ceramic crowns. Am J Dent 8, 259-262.

4. Reich S, Petschelt A, Lohbauer U (2008) The effect of finish line preparation and layer thickness on the failure load and fractography of $\mathrm{ZrO}_{2}$ copings. J Prosthet Dent 99, 369-376.

5. Tyas MJ, Anusavice KJ, Frencken JE, Mount GJ (2000) Minimal intervention dentistry - a review. FDI Commission Project 1-97. Int Dent J 50, 1-12.

6. Preston JD (1977) Rational approach to tooth preparation for ceramo-metal restorations. Dent Clin North Am 21, 683-698.

7. Kuwata M (1980) Theory and practice for ceramo metal restorations. Quintessence, Chicago, 35.

8. Shillingburg HT (1997) Fundamentals of fixed prosthodontics. 3rd ed, Quintessence, Chicago, 142-151.

9. Lawn BR, Deng Y, Lloyd IK, Janal MN, Rekow ED, Thompson VP (2002) Materials design of ceramic-based layer structures for crowns. J Dent Res 81, 433-438.

10. Webber B, McDonald A, Knowles J (2003) An in vitro study of the compressive load at fracture of Procera AllCeram crowns with varying thickness of veneer porcelain. J Prosthet Dent 89, 154-160.

11. Lawn BR, Pajares A, Zhang Y, Deng Y, Polack MA, Lloyd IK et al. (2004) Materials design in the performance of allceramic crowns. Biomaterials 25, 2885-2892.

12. Guazzato M, Proos K, Quach L, Swain MV (2004) Strength, reliability and mode of fracture of bilayered porcelain/zirconia (Y-TZP) dental ceramics. Biomaterials 25, 5045-5052.

13. Guazzato M, Proos K, Sara G, Swain MV (2004) Strength, reliability, and mode of fracture of bilayered porcelain/core ceramics. Int J Prosthodont 17, 142-149.

14. Raigrodski AJ (2005) All-ceramic full-coverage restorations: concepts and guidelines for material selection. Pract Proced Aesthet Dent 17, 249-256; quiz 258.
15. Rekow ED, Harsono M, Janal M, Thompson VP, Zhang G (2006) Factorial analysis of variables influencing stress in all-ceramic crowns. Dent Mater 22, 125-132.

16. Shokry TE, Shen C, Elhosary MM, Elkhodary AM (2006) Effect of core and veneer thicknesses on the color parameters of two all-ceramic systems. J Prosthet Dent 95, 124-129.

17. Raigrodski AJ (2004) Contemporary materials and technologies for all-ceramic fixed partial dentures: a review of the literature. J Prosthet Dent 92, 557-562.

18. Denry I, Kelly JR (2008) State of the art of zirconia for dental applications. Dent Mater 24, 299-307.

19. Davis GR, Tayeb RA, Seymour KG, Cherukara GP (2012) Quantification of residual dentine thickness following crown preparation. J Dent 50, 571-576.

20. Wheeler RC (1954) Tooth form: drawing and curving. WB Sanders.

21. Stambaugh RV, Wittrock JW (1977) The relationship of the pulp chamber to the external surface of the tooth. J Prosthet Dent 37, 537-546.

22. Oden A, Andersson M, Krystek-Ondracek I, Magnusson D (1998) Five-year clinical evaluation of Procera AllCeram crowns. J Prosthet Dent 80, 450-456.

23. Proos KA, Swain MV, Ironside J, Steven GP (2003) Influence of core thickness on a restored crown of a first premolar using finite element analysis. Int J Prosthodont 16, 474-480.

24. Beuer F, Aggstaller H, Edelhoff D, Gernet W (2008) Effect of preparation design on the fracture resistance of zirconia crown copings. Dent Mater J 27, 362-367.

25. Beuer F, Edelhoff D, Gernet W, Naumann M (2008) Effect of preparation angles on the precision of zirconia crown copings fabricated by CAD/CAM system. Dent Mater J 27, 814-820.

26. Patroni S, Chiodera G, Caliceti C, Ferrari P (2010) CAD/CAM technology and zirconium oxide with feather-edge marginal preparation. Eur J Esthet Dent 5, 78-100.

27. Martignoni M, Schoenberger A (1990) Precision fixed prosthodontics clinical and laboratory aspect. Quintessence, Berlin, 580.

28. Blair FM, Wassell RW, Steele JG (2002) Crowns and other extra-coronal restorations: preparations for full veneer crowns. Br Dent J 192, 561-564, 567-571.

29. Massironi D, Pascetta R, Romeo G (2005) Precision in dental esthetics: clinical procedures. Quintessence, Berlin, 400.

30. Chandler NP (1989) The radiographic assessment of pulp size: validity and clinical implications. N Z Dent J 85, 23-26.

31. Murray PE, Lumley PJ, Smith AJ (2002) Preserving the vital pulp in operative dentistry: 3 . Thickness of remaining cavity dentine as a key mediator of pulpal injury and repair responses. Dent Update 29, 172-178.

32. Murray PE, About I, Lumley PJ, Franquin JC, Remusat M, Smith AJ (2002) Cavity remaining dentin thickness and pulpal activity. Am J Dent 15, 41-46.

33. Murray PE, Coffman JA, Carcia-Godoy F (2004) Pulp responses to remaining dentin thickness. Todays FDA 16, 17-19.

34. Ericson S, Hedegård B, Wennström A (1966) Roentgeno- 
graphic study of vital abutment teeth. J Prosthet Dent 16, 981-987.

35. Bergenholtz G, Nyman S (1984) Endodontic complications following periodontal and prosthetic treatment of patients with advanced periodontal disease. J Periodontol 55, 63-68.

36. Karlsson S (1986) A clinical evaluation of fixed bridges, 10 years following insertion. J Oral Rehabil 13, 423-432.

37. Cheung GS, Dimmer A, Mellor R, Gale M (1990) A clinical evaluation of conventional bridgework. J Oral Rehabil 17, 131-136.

38. Cheung GS (1991) A preliminary investigation into the longevity and causes of failure of single unit extracoronal restorations. J Dent 19, 160-163.

39. Jackson CR, Skidmore AE, Rice RT (1992) Pulpal evaluation of teeth restored with fixed prostheses. J Prosthet Dent 67, 323-325.
40. Valderhaug J, Jokstad A, Ambjørnsen E, Norheim PW (1997) Assessment of the periapical and clinical status of crowned teeth over 25 years. J Dent 25, 97-105.

41. Saunders WP, Saunders EM (1998) Prevalence of periradicular periodontitis associated with crowned teeth in an adult Scottish subpopulation. Br Dent J 185, 137-140.

42. Walton TR (1999) A 10-year longitudinal study of fixed prosthodontics: clinical characteristics and outcome of singleunit metal-ceramic crowns. Int J Prosthodont 12, 519-526.

43. Cheung GS (2002) Survival of first-time nonsurgical root canal treatment performed in a dental teaching hospital. Oral Surg Oral Med Oral Pathol Oral Radiol Endod 93, 596-604.

44. Cheung GS, Lai SC, Ng RP (2005) Fate of vital pulps beneath a metal-ceramic crown or a bridge retainer. Int Endod J 38, 521-530. 